\title{
The Nexus between Misallocation of Land Resources and Green Technological Innovation: A Novel Investigation of Chinese Cities
}

\section{Xincai Gao}

Lanzhou University

\section{Shuai Wang}

Lanzhou University

Fayyaz Ahmad ( $\square$ fayyaz@lzu.edu.cn )

Lanzhou University https://orcid.org/0000-0001-9038-0817

\section{Abbas Ali Chandio}

Sichuan Agricultural University - Chengdu Campus

\section{Munir Ahmad}

Zhejiang University

\section{Dan Xue}

\section{Lanzhou University}

\section{Research Article}

Keywords: Misallocation of Land Resources, Green Technology Innovation, Economic Development, Environmental Regulation

Posted Date: February 8th, 2021

DOl: https://doi.org/10.21203/rs.3.rs-168330/v1

License: (c) (i) This work is licensed under a Creative Commons Attribution 4.0 International License. Read Full License 


\title{
The nexus between misallocation of land resources and green
}

$$
\text { technological innovation: A novel investigation of Chinese cities }
$$

\author{
Xincai Gao ${ }^{1}$ \\ ${ }^{1}$ School of Economics, Lanzhou University Lanzhou 73000, Gansu, China \\ Email: jgygxc@1zu.edu.cn \\ Shuai Wang 1 \\ ${ }^{1}$ School of Economics, Lanzhou University Lanzhou 73000, Gansu, China \\ Email: wangsh2019@1zu.edu.cn
}

\author{
Fayyaz Ahmad ${ }^{1, *}$ \\ ${ }^{1}$ School of Economics, Lanzhou University Lanzhou 73000, Gansu, China \\ Email: fayyaz@1zu.edu.cn
}

\author{
Abbas Ali Chandio ${ }^{2, * *}$ \\ ${ }^{2}$ College of Economics, Sichuan Agricultural University, Chengdu 611130, China \\ Email: alichandio@sicau.edu.cn \\ Munir Ahmad ${ }^{3}$ \\ ${ }^{3}$ School of Economics, Zhejiang University, Hangzhou 310058, China \\ Email: munirahmad@zju.edu.cn \\ Dan Xue ${ }^{1}$ \\ ${ }^{1}$ School of Economics, Lanzhou University Lanzhou 73000, Gansu, China \\ Email: xuedan2748409@163.com \\ *Correspondence: fayyaz@1zu.edu.cn; alichandio@sicau.edu.cn
}

\begin{abstract}
As an important production factor, land resources significantly impact green technology innovation (GTI). However, the misallocation of land resources caused by the government's "secondhand" land supply strategy has become increasingly prominent, which will adversely affect GTI by affecting the allocation of innovative elements. Based on the research data of 252 cities in China from 2008 to 2017, this paper uses panel space measurement estimation and panel threshold estimation empirical methods to test the theoretical hypothesis of the impact of misallocation of land resources on GTI. The study finds that local or neighboring land resources' misallocation has a hindering effect on local GTI. Furthermore, the misallocation of land resources has a threshold effect on the impact of GTI. The relatively high level of local economic development and environmental regulation reduces the restraining effect of the misallocation of land resources on GTI, and vice versa. Therefore, local
\end{abstract}


governments should optimize the allocation of innovative elements, accelerate the construction of an

35 efficient and market-oriented green technology innovation system, reduce the excessive intervention in

36 land resources, and enhance the vitality of innovation entities to improve the level of green technology 37 innovation.

38

39

40

Key words: Misallocation of Land Resources; Green Technology Innovation; Economic Development;

41 Environmental Regulation 


\section{Introduction}

With the continuous development of urbanization and industrialization, China's environmental problems have become increasingly prominent, and the long-term extensive development model has made economic and social development fall into the cycle of confusion of "environment-economy". As a key way to realize the coordinated development of economic growth and ecological protection, green technology innovation (GTI) is also a hot topic of the general concern in society (Show et al. 2018, Usui et al. 2017). To accelerate ecological civilization construction, it has been put forward in the reports of the 19th National Congress of the Communist Party of China that we should build a market-oriented system for green technology innovation to lead to green economic and social development. Meanwhile, the National Development and Reform Commission and the Ministry of Science and Technology have jointly issued the Guidelines on Building a Market-oriented Green technology innovation System. It has strengthened the role of technology innovation in green development and emphasized establishing a green, low-carbon, and circular economic development system by promoting GTI. And, finally, it has become an internal requirement of the harmonious development of economy and environment. In addition, as an important emerging technology, GTI plays an important role in enhancing China's position in the new round of industrial revolution and science and technology competition (Luo and Zhang 2020). In recent years, China has made great progress in building an innovation-oriented country and made great breakthroughs in green technology innovation. According to data from the State Intellectual Property Office, from 2014 to 2017, China's green technology patent applications have reached 249,000, and green technology patents applied for in China have accounted for 89.96\%. However, the problems such as a small number of core patents, urgent need to improve the quality of patents, and owe conversion rate of results, etc., ${ }^{1}$ still exist. It makes the current level of green technology innovation still disjointed with the actual demand, becoming the bottleneck restricting green development.

In March 2020, the CPC Central Committee and the State Council issued the opinions on building a more complete "Mechanism for Market-based Allocation of Factors of Production." It proposed that the market-oriented reform of factors of production should be deepened, the efficiency of factor allocation should be improved, and the creativity of the whole society to promote high-quality economic development must be stimulated. Among them, as a core element in the production process, the land has an important influence on enterprises' innovation activities. Moreover, as an important resource in the process of local urbanization and industrialization, the land factor has the function of "generating wealth and attracting capital", which will make land become the target of competition for local governments. In particular, under the dual incentives of fiscal and political performance, local governments tend to rely on land transfer to drive local growth; as a result, the government intervenes excessively in the land factor market, distorting the allocation of land factor. Since the implementation of the "bid, auction, and listing" system in November $2007^{2}$, the transfer of industrial land, based on agreement and industrial land transfer at ultra-low prices by local governments, has decreased. However, the phenomenon of "attracting investment at low prices" by local governments is still stern, and extensive land resources' use will lead to low-quality repetitive construction in some industries. It might even result in the rapid development of enterprises with high emissions and high pollution, and restrain their technology

${ }^{(1)}$ Data from Chinese Science News, by Zheng Jinwu http://news.sciencenet.cn/htmlnews/2020/5/439297.shtm?id=439297

${ }^{2}$ The "Bid, auction and listing" system refers to the Regulations on the Transfer of State-owned Construction Land Use Right by Bid, Auction and Listing. 
innovation impetus. So, does the current misallocation of land resources hinder regional green technology innovation? The existence of a certain spatial interactive relationship between misallocation of land resources, technology research and development, and green technology innovation raises an important query. What is the impact of misallocation of local land resources on green technology innovation in local and adjacent areas? Considering that there are certain differences in natural factor endowments and economic and social development, what is the impact of misallocation of land resources under different green technology innovation conditions? Though the above-stated questions are of great significance to clarifying the role of land resource allocation in the development of green technology innovation, they were overlooked by the previous studies. Therefore, under the background of China's major strategies, including vigorously advocating the concept of "green, innovative" development, deepening market-oriented reform of factors of production, accelerating ecological civilization construction and building a beautiful China, it is of important practical significance to study the influence of misallocation of local land resources on green technology innovation in the current research.

As for the research on green technology innovation, several scholars mainly focused on discussing the influencing factors, especially, they have carried out a plethora of research on the governmental factors. Green technology can reduce environmental pollution, reduce energy consumption, and improve ecological environment quality (Braun et al. 1994). Considering the negative externality of environmental resource utilization and the uncertainty and overflowing of technology innovation, the development of green technology innovation can hardly be achieved without government guidance and support (Guo et al. 2018). On the one hand, to correct the negative externality of resource use, the government must adopt environmental regulation to constrain resources through public means to force the upgrading of green technology innovation. Some scholars found that in some industries, the government's environmental regulation measures can promote the innovation and diffusion of green technology (Mickwitz et al., 2008). However, the impact of environmental regulation on green technology innovation is not always positive, but varies according to the choice of environmental regulation tools. Market-oriented environmental regulation tools have a more significant positive impact on green technology innovation than command-and-control tools (Guo, 2019; Miao et al. 2019).

Some scholars investigated the impact of environmental regulation intensity on green technology innovation, and they found that only under certain conditions can high-intensity environmental regulation promote green technology innovation ( $\mathrm{Li}$ et al. 2013, Wang et al. 2015). In addition, there are also a few scholars who analyzed the impact of opening to the outside world and board governance under environmental regulation on green technology innovation (Jing and Zhang 2014; Wang et al. 2015). On the other hand, Zang et al. (2017) suggested that the uncertainty and the positive overflowing of green technology innovation have contributed to insufficient investment in R\&D for technology innovation of the innovative subject. Therefore, green technology innovation development needs external incentives of the government's subsidy policies to correct the positive externality caused by technological spillovers. He (2019) stated that the government's support for the innovative subject could make up for the deficiency in the R\&D of green technology innovation. However, Dominique said that government subsidies might generate a crowding-out effect while encouraging the innovative subject to invest in the R\&D of green technology innovation (Guellec and Bruno 2003). This is because more government subsidies for the environment are not always better; instead, more attention should be paid to the utilization rate of government subsidies by the innovation subject (Fan and Zhu 2019). In addition, based on government subsidies and analysis of enterprises' internal resources, $\mathrm{Wu}$ and $\mathrm{Hu}(2020)$ found that the synergetic effect of government subsidies and idle resources within enterprises can effectively 
promote enterprises' green technology innovation.

Generally, there are abundant researches on the influencing factors of green technology innovation. However, the existing research focused on government and enterprises' behaviors, mostly focusing on the provincial and regional levels, and the research level is relatively macroscopic. Also, there are a bunch of studies on the spatial spillover effect of green technology innovation, and insufficient attention has been paid to the spatial correlation effect of green technology innovation. At present, there is little literature on the influence of factor allocation on green technology innovation, and most of the pieces of literature focused on the analysis of general technology innovation. Firstly, in terms of the influence of factor allocation on technology innovation, Jefferson et al. (2017) showed that the improvement of innovation level not only comes from the increase of R\&D investment, but also is inseparable from the improvement of use efficiency of factor resources in the innovation process. Zhang et al. (2011) put forward that the more serious the factor market's distortion, the stronger its inhibition to enterprise R\&D investment will be, resulting in a lock-in effect on the technological level. Secondly, some scholars also analyzed the influence of misallocation of different resources on enterprise innovation. For example, Hsieh and Klenow (2008) believed that capital and labor resources' misallocation would reduce total factor productivity and innovation output. Bai and Bian (2017) also found that the distortion of labor and capital factor markets significantly inhibited the innovative production activities. However, Lv and Wang (2019) showed that the misallocation of labor resources might promote enterprise innovation, and the misallocation of capital resources demonstrated no significant effect on enterprise innovation.

Finally, there are a few pieces of research on the relationship between land resource allocation and technology innovation. The existing studies on the misallocation of land resources mainly focused on the government competition (Luo and $\mathrm{Li}$ 2014), industrial enterprise productivity ( $\mathrm{Li}$ et al. 2016), environmental pollution (Yu et al. 2019), economic development quality (Zhang et al. 2019), upgrading of an industrial structure (Lai 2019), and the economic fluctuation (Song et al. 2020). A few works have only covered technology innovation. For example, in the process of analyzing the misallocation of land resources and upgrading of an industrial structure, Lai (2019) found that the distortion of land resources would inhibit the development of high-end production and service industries, making it difficult to transform the technology research and development and their outcomes. Meanwhile, the government is the actual monopolist of land factor, and the distorted development view of "seeking development by land" of the local governments may lead to the misallocation of land resources, making the industrial enterprises lack the enthusiasm for innovation (Yu et al. 2019). On the whole, some progress has been achieved in the existing researches, but most of them are concentrated on the study of the influence of misallocation of resources on technology innovation. Some studies discussed the effect of land resources' misallocation on green technology innovation; though, insufficient attention has been paid to the possible threshold effect, which needs to be further supplemented and improved.

In view of this, by taking 252 prefecture-level cities in China from 2008 to 2017 as the research objects, this paper has systematically investigated the impact of misallocation of land resources on green technology innovation through the building and estimation of the Spatial Durbin Model and Panel Threshold Model. This paper has made a significant contribution to the several aspects. For example, firstly, a theoretical mechanism of the possible spatial correlation effect and threshold effect of the misallocation of land resources on green technology innovation is proposed to sort out the influencing mechanism and practical analysis of the misallocation of land resources. Secondly, most of the existing research ignored the possible spatial correlation effect of government-led land resources allocation, 
resulting in a deviation in the measurement results. Using the panel space measurement estimation, this paper has made a more scientific and comprehensive investigation of the impact of land resources' misallocation on green technology innovation from a spatial perspective. Finally, this paper used the green patent data of different cities, which was obtained from the State Intellectual Property Office (SIPO) based on the green patent IPC number provided by the World Intellectual Property Organization (WIPO). This specific data helps to investigate the impact of land resources allocation on green technology innovation at a micro-level.

\section{Theoretical Mechanism and Research Hypothesis}

\subsection{Spatial correlation effect of the misallocation of land resources on green technology innovation}

The land is an important tool for local governments to achieve economic growth, and there is a strategic interaction between the prices and modes of land supply, that is, when a local government sells industrial land at a low price or by agreement, the neighboring regions may adopt dominant strategies as much as possible in order to maximize their own interests, and learn and imitate the land transfer behavior of the surrounding local governments (Duan and Li, 2020). This results in the spatial correlation effect of misallocation of land resources between regions. As a kind of technology innovation, green technology innovation is also featured with technology spillover, which is specifically manifested in spatial viscidity of tacit knowledge in the process of innovation, as well as a direct proportion between distance and knowledge diffusion cost. It encourages neighboring regions to learn advanced green technology and management experience through continuous imitation to drive local green technology progress. Thus, forming the "neighborhood imitation" mechanism of green technology innovation between regions (Lu and Bai 2020). It suggests that there are spatial spillover effects of green technology innovation. Since there are spatial spillover effects of misallocation of land resources and green technology innovation between regions, there may also be a certain degree of spatial correlation effect concerning the impact of misallocation of land resources on green technology innovation.

The impact of misallocation of land resources on green technology innovation may be divided into two aspects. Firstly, the impact of misallocation of land resources on local green technology innovation indicates that industrial land sale at a cheap price will attract industrial enterprises with low quality and high energy consumption to settle in. This may result in the distorted price of land resources and misallocation of resources between industry and services, thus hindering innovative energy saving and emission reduction technology (Huang and Du 2017). Meanwhile, to make up for the industrial land sale at a low price, a "second-hand" land supply strategy of raising the price of commercial and residential land may contribute to wantonly development of the real estate, construction, and other related industries with low technical content and high pollution and energy consumption. It hinders the transformation and upgrading of industrial structure, which is not conducive to the green technology innovation (Lai 2019). In addition, in the case of misallocation of land resources, it is difficult for land resources to flow from low-productivity enterprises to high-productivity enterprises. However, when the land costs of lowproductivity enterprises are low, it may be confined to the current production efficiency and low technical 
level, which will also be detrimental to green technology's progress and innovative development (Zhang et al. 2019). Secondly, the impact of misallocation of land resources in adjacent areas on local green technology innovation suggests that with dual incentives of fiscal and political performance, the demonstration-mimic diffusion mechanism of misallocation of land resources will set a good example for the local governments. However, the local governments attract the industries of pollution and low quality by imitating and learning from their neighboring governments' behaviors to maximize the local interests, which hinders the development of local green technology innovation. Furthermore, the local governments compete for growth, and they tend to compete with each other by means of selling industrial land at a cheap price by attracting capital (Luo and Li 2014). This means that under a system that GDP still serves as the main criteria of assessment, the local governments attract capital into the region through the misallocation of resources with distorted land prices. To achieve economic growth and stand out in the assessment, neighboring local governments will also use the land to compete for space, and they may even compete to lower the local environmental standards (Luo and $\mathrm{Li}$ 2014). Therefore, polluting enterprises' flexible regulations hinder the local green technology innovation (Yang et al. 2014). Finally, with the misallocation of adjacent land resources inhibits the development of local green technology innovation, the positive spillover effect of inter-regional green technology innovation is weakened, and to some extent, the green technology exchange and factor mobility are blocked (Lu and Bai 2020). Thus, this misallocation hinders the development of local green technology innovation. Based on the above analysis, the following research hypothesis is proposed in this paper:

Hypothesis 1: Misallocation of local and adjacent land resources will hinder local green technology innovation.

\subsection{Threshold effect of the misallocation of land resources on green technology innovation}

Based on the existing research, it can be found that land, labor, and capital are important factors of production, and there are strong complementary characteristics between land and the other two factors. Therefore, the misallocation of land resources will also contribute to distortions in the allocation of other resources, and it is detrimental to green technology innovation by influencing the allocation of innovation factors of enterprises ( $\mathrm{Li}$ et al. 2016). However, since there are differences in local economic development levels and natural factor endowments, the impact of misallocation of land resources on green technology innovation will be affected by many factors. For example, Luo and Li (2014) found that the misallocation of land resources caused by the introduction of capital by selling land at a low price had been at a "white-hot" stage in the eastern region. Conversely, imitation competition in the central region is also at the start-up stage, and it is upgrading in the western region. Shu et al. (2018) also showed differences in the degree of utilization of land resources in different regions, which vary with the city's size. Therefore, in this paper, it is believed that there is a certain threshold effect on the impact of misallocation of land resources on green technology innovation. It implicates that the impact of misallocation of local land resources on green technology innovation will vary depending on local conditions. 
On the one hand, land resources are an important starting point for the local governments to develop the economy. The local governments will sell large quantities of industrial land at a low price to seek economic growth. In particular, some economically underdeveloped areas that lack a soft environment to attract capital inflows are more inclined to transfer through low price and agreement to achieve development (Zhang et al. 2019). It means that with the improvement of the level of local economic development, the financial pressure faced by the local governments has been alleviated, the practice of "seeking development by land" is reduced, and the resistance to industrial structure transformation and upgrading will be reduced accordingly, alleviating the hindrance and inhibition on green technology innovation. On the other hand, the distortion of resource allocation will inhibit the local environmental welfare performance (Song and Jin 2016). When the level of economic development rises to a certain level, the local residents' demand for public service, environment, etc., has been strengthened. This, in turn, encourages the local governments to adopt the policies that meet public preferences (Cai et al. 2018). In other words, the "vicious competition" for land sales by local governments and the settlement of industrial enterprises with low quality and high pollution emissions will be reduced, and the regional environmental performance will be improved. This is beneficial to reduce the hindrance of misallocation of land resources on green technology innovation. Therefore, based on the above analysis, the following research hypothesis is proposed in this paper:

Hypothesis 2.1: The inhibition effect of misallocation of land resources on green technology innovation will be alleviated only when the level of local economic development is high.

Similarly, the impact of differences in the degree of environmental regulation is also important in this regard. For example, Lu and Bai (2020) proposed that there will be less "competition" among local governments to attract capital inflows at the expense of the environment and resources with a strengthened degree of environmental regulation. Meanwhile, there will also be less competition for space to sell lots of cheap lands, making the transfer and pricing methods of industrial land and commercial land more standardized. As a result, the degree of price distortion of land factor and the crowding-out effect of enterprises' rent-seeking activities on green technology innovation will accordingly reduce. On the other hand, when the level of environmental regulation is raised to a certain extent, it will promote green technology progress as well as energy conservation and emission reduction technology diffusion of enterprises, and make enterprises pay more attention to production process improvement and pollution control. This shows that with the improvement of the degree of environmental regulation, the environmental protection threshold of regional foreign capital inflow is further raised, and the quality of foreign industrial enterprises attracted by the misallocation of land resources has been improved. This, in turn, further improves the regional innovation environment and helps alleviate the inhibition of green technology innovation caused by the misallocation of land resources. Therefore, based on the above analysis, the following research hypothesis is proposed in this paper:

Hypothesis 2.2: The inhibition effect of misallocation of land resources on green technology 


\subsection{Data Sources and Statistical Description}

Given the availability and uniformity of data, in this paper, measurement analysis and robustness test are performed respectively by taking 252 prefecture-level cities in China from 2008 to 2017 and from 2009 to 2017 as the research objects. All indicators that involve price factors in the data are treated in a constant price manner based on the year 2000. Based on the IPC number shown in the green patent list published by the World Intellectual Property Organization (WIPO), the green patent data for green technology innovation measurement is obtained by hand sorting by the author and through patent retrieval in State Intellectual Property Office (SIPO). The data of misallocation of land resources comes from the China Land and Resources Statistical Yearbooks and the China Land \& Resources Almanac; other data comes from the China City Statistical Yearbooks and the China Statistical Yearbooks on Environment.

Table 1 Statistical description of variables

\begin{tabular}{|c|c|c|c|c|c|c|}
\hline Variable & Unit & $\begin{array}{l}\text { Number of } \\
\text { Samples }\end{array}$ & Average & $\begin{array}{l}\text { Minimum } \\
\text { Value }\end{array}$ & $\begin{array}{c}\text { Maximum } \\
\text { Value }\end{array}$ & $\begin{array}{l}\text { Standard } \\
\text { Deviation }\end{array}$ \\
\hline gt & - & 2520 & -1.009 & -4.605 & 5.932 & 3.098 \\
\hline $\mathrm{mlr}$ & - & 2520 & 0.113 & 0 & 2.290 & 0.140 \\
\hline fdi & $\%$ & 2520 & 2.003 & 1.876 & 0.010 & 19.88 \\
\hline gi & $\%$ & 2520 & 25.60 & 1 & 372.1 & 36.96 \\
\hline grd & $\%$ & 2520 & 1.642 & 0.070 & 20.68 & 1.564 \\
\hline indus & $\%$ & 2520 & 49.49 & 13.85 & 85.08 & 9.544 \\
\hline $\mathrm{h}$ & Year/Person & 2520 & 0.806 & 0.190 & 2.620 & 0.389 \\
\hline ey & $\begin{array}{c}\text { Ten } \\
\text { thousand } \\
\text { Yuan }\end{array}$ & 2520 & 1.324 & 0.01 & 13.47 & 0.878 \\
\hline er & $\begin{array}{c}\text { Ten } \\
\text { thousand } \\
\text { Yuan/ton }\end{array}$ & 2520 & 4.452 & 0.004 & 10000 & 199.2 \\
\hline lem & - & 2268 & 0.312 & 0.005 & 0.851 & 0.155 \\
\hline
\end{tabular}

254

\subsection{Basic Framework and Variable Description}

1. Model and variable description. Based on the above analysis and proposed research hypothesis, in this paper, the following basic model is established by reference to the practices of Lu and Bai (2020).

$$
g t_{i, t}=\alpha_{0}+\alpha_{1} m l r_{i, t}+\delta X_{i, t}+\varepsilon_{i, t}
$$

Where, $i$ and $t$ represent area and year respectively, $X$ represents control variable, $\alpha_{0}$ represents constant, $\alpha_{1}$ and $\delta$ represent the measurement estimate coefficient of each influencing 
factor, and $\varepsilon$ represents the random disturbance term.

(1) Explained variable: $g t$ represents the level of regional green technology innovation. Based on the existing research, it is widely believed that green technology innovation is an effective means to coordinate economic development and environmental protection (He 2014). By taking the practices of Dong and Wang (2019) as a reference, in this paper, green patent data at the city level is obtained to measure the level of green technology innovation through patent retrieval at the State Intellectual Property Office (SIPO) and based on IPC number shown in the green patent list published by the World Intellectual Property Organization (WIPO).

(2) Core explanatory variable: $m l r$ represents the degree of misallocation of regional land resources. Most of the existing studies believe that the "agreement transfer" can be regarded as a synonym for "low-cost transfer" and "industrial land", meanwhile, the price index of industrial land cannot reflect the quality of investment projects (Yang et al. 2014). Therefore, this paper takes the practice of $\mathrm{Li}$ et al. (2016) as a reference. Since no industrial land transfer data of different cities is directly released in the existing yearbooks, this paper used the ratio of agreed leased land area to the total leased land area in different cities as the proxy variable of the proportion of leased industrial land to measure the degree of the misallocation of land resources. In addition, some industrial land may be sold in other ways; however, the "reinvigoration" of the construction land reserve is also an important index to measure the degree of land resource allocation. Therefore, to investigate the allocation of regional land resources in a more comprehensive way, the ratio of the transferred area of industrial and mining storage land in different cities is used to measure the degree of misallocation of regional land resources, and a robustness test was performed to the results.

(3) Other control variables: ey is the level of regional economic development, which is an important factor that affects regional green technology innovation. In this paper, the real per capital gross regional product is used to measure the level of economic development (Guo 2019). $f d i$ is the level of attracting foreign investment of the region, which is measured based on the proportion of the total amount of foreign direct investment actually used by each city in the gross regional domestic product (Dong and Wang 2019). $g i$ is the level of regional administrative control, which is expressed based on the proportion of local government fiscal expenditure in the gross regional domestic product (Dong and Wang 2019). grd is the level of regional R\&D investment, which is measured based on the proportion of government technical expenditures in general fiscal expenditure ( $\mathrm{Lu}$ and Bai 2020). indus is the regional industrial structure, which is expressed with the proportion of the added value of the secondary industry in the gross regional domestic product (Guo 2019). $h$ is regional human capital, and human capital is an important innovation input factor during technology innovation, which has an important influence on the R\&D and innovation of green technology; it is expressed with the proportion of the number of enrolled students $\times 10+$ college students $\times 15$ at all middles schools of all cities in the total urban population based on the method of years of schooling. 
(4) The threshold effect takes the influence of the degree of regional environmental regulation into account. The reciprocal value of the ratio of discharge amount of wastewater to gross regional domestic product is used to measure the degree of regional environmental regulation. It means, the smaller the discharge amount of wastewater per unit GDP is, the larger the index and the higher the degree of environmental regulation will be, and vice versa.

\subsection{Measurement Model and Methods}

Considering that there may be technology spillover and exchange among regions in terms of green technology innovation, and there is also significant demonstration-imitation behavior in the misallocation of land resources between adjacent areas, to test the theoretical hypothesis 1 proposed in this paper, the spatial correlation effect between regions should be taken into account during measurement estimation. Meanwhile, to evaluate the effects of misallocation of land resources and other influencing factors in adjacent areas on green technology innovation, in this paper, Spatial Durbin Model (SDM) is adopted, the spatial lag term of misallocation of land resources in adjacent areas and the spatial lag term of other control variables are introduced in the measurement model. Therefore, the measurement model for spatial correlation in this paper is shown as follows:

$$
g t_{i, t}=\beta_{0}+\beta_{1} m l r_{i, t}+\beta_{2} W m l r+\gamma X_{i, t}+\eta W X_{i, t}+\sigma_{i, t}
$$

In equation (2), $W$ represents $N \times N$ dimensional spatial weight matrix, including economic, geographical, and blend weights. Where, the geographical weight matrix shall be $W_{d}=1 / d_{\mathrm{ab}}^{2}, a \neq b$, otherwise, it should be 0 ; the economic weight matrix should be $W_{e}=1 /\left|g d p_{a}-g d p_{b}\right|, a \neq b$, otherwise, it should be 0 ; the blend weight matrix should be $W_{m}=W_{d} / W_{e} . \quad W X_{i, t}$ and $W m l r_{i, t}$ represent the spatial lag term of the misallocation of land resources and the control variables, respectively.

The theoretical hypothesis 2 proposed in this paper indicates that the misallocation of land resources may exert the threshold effect of the level of economic development and the degree of environmental regulation on green technology innovation. To investigate the possible threshold effect, the economic development level and the environmental regulation degree are respectively introduced into the measurement model (1) as unknown variables to construct piecewise function of the misallocation of land resources to green technology innovation, and examine the threshold value and the threshold effect. The corresponding measurement model of the single threshold effect is shown as follows:

$$
g t_{i, t}=\mu_{0}+\mu_{1} m l r_{i, t}+\mu_{2} m l r_{i, t} I_{i, t}(t h \leq \theta)+\mu_{3} m l r_{i, t} I_{i, t}(t h>\theta)+\lambda X_{i, t}+\pi_{i, t}
$$

In equation (3), th represents the threshold variable; namely, the level of economic development and the degree of environmental regulation, $\theta$ represents the threshold value, and $I(\bullet)$ is the corresponding indicator function of the threshold effect.

\section{Measurement Estimation and Analysis}

\subsection{Unit root test}



there may be differences in panel data's unit root, this paper adopts the LLC test and PP-Fisher test. The stationary test results of panel data are shown in Table 2. According to the results in the Table 2, the null hypothesis of unit root is rejected for all variables at least at the 5\% significance level.

Table 2 Stationary tests results

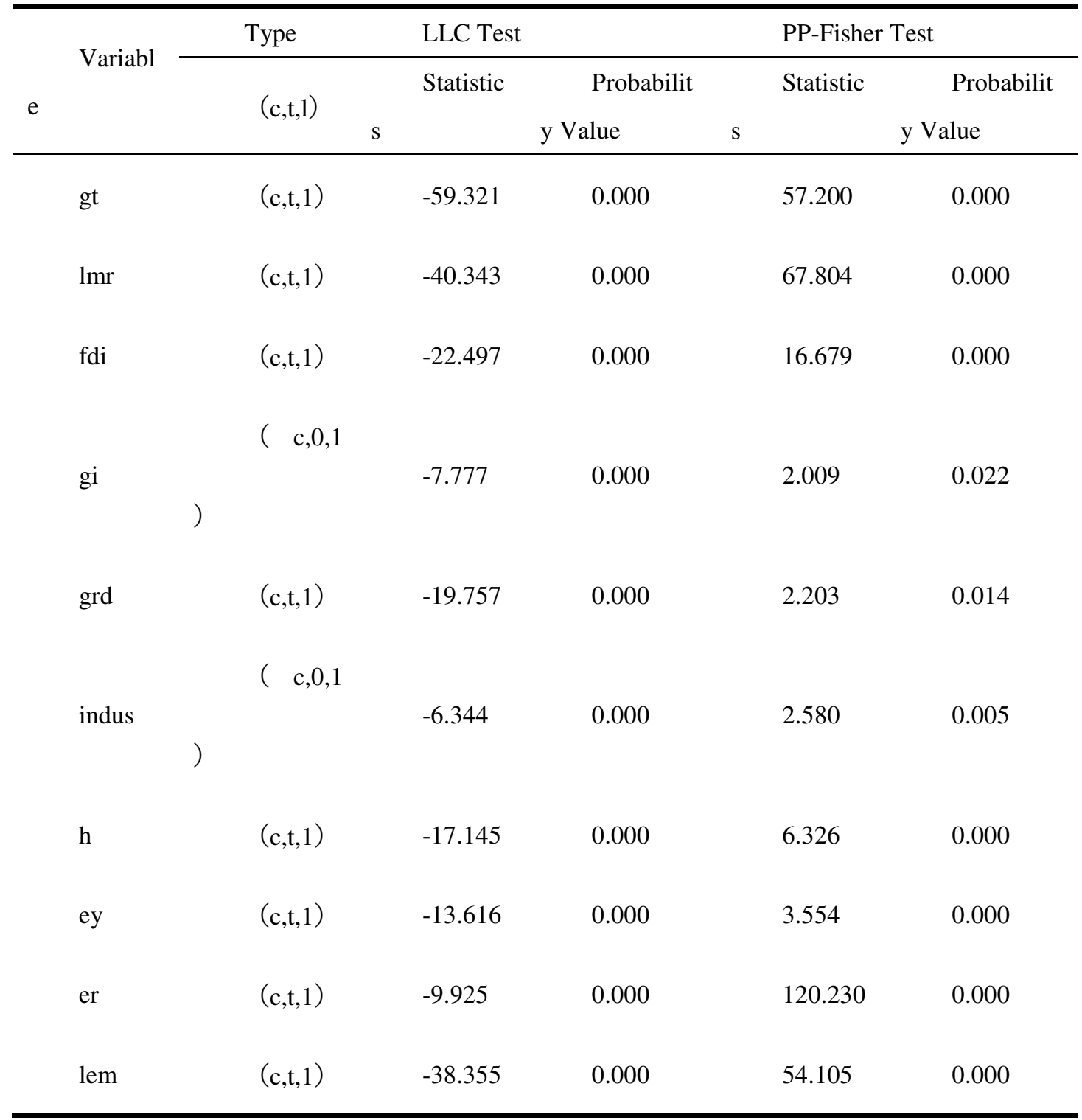

Note: $\mathrm{c}, \mathrm{t}, 1$ indicate having a constant term, trend term and lag order, respectively.

1. Cross-Sectional Dependence test

When panel data is used for measurement estimation, there will be a strong correlation between the sections in some cases, which may be caused by the common economic impact that affects the dependent

343 variables and the failure to introduce the model for the unidentified components, thus automatically

344 becoming part of the error term. Therefore, in this paper, the Pesaran test and Frees test are adopted to perform the Cross-sectional dependence (CD) test on the model. The results are shown in Table 3. 
Pesaran and Frees' test values are 69.053 and 6.226, and both of them pass the significance test at the $1 \%$ level, which indicates that there is $\mathrm{CD}$ in the data.

Table 3 Cross-Sectional Dependence Test results

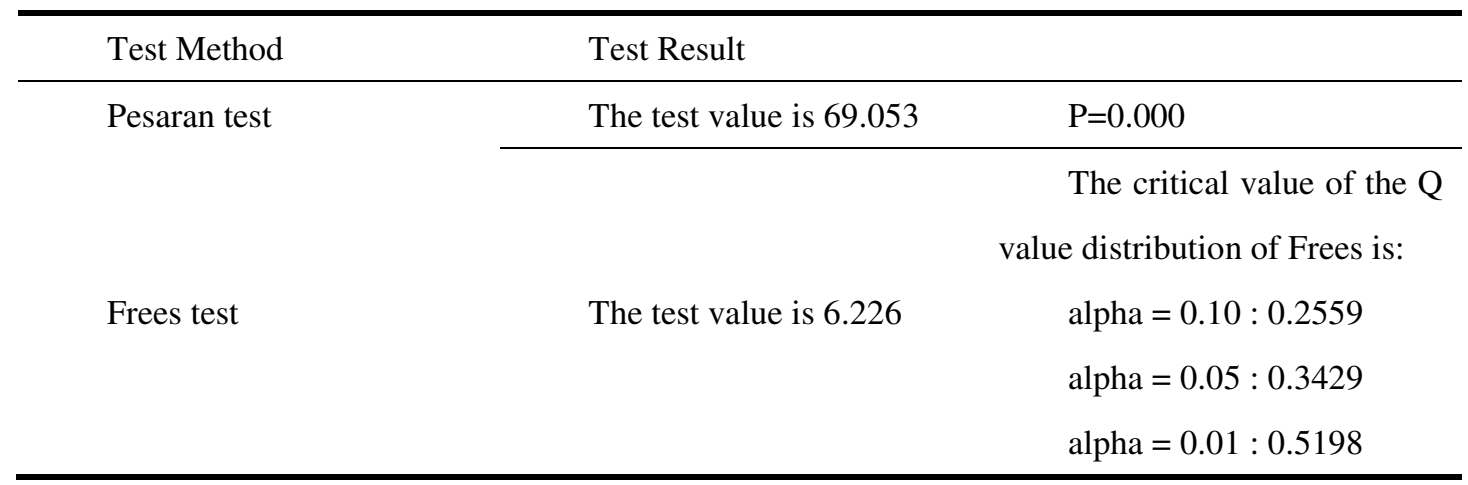

350

351

\section{Spatial correlation test}

After it is confirmed that there is cross-sectional dependence of the panel data, in this paper, Moran's I spatial correlation test statistics is adopted to determine the spatial correlation of misallocation of land resources in various regions. The results are shown in Table 4. It can be found that the Moran's I value under the economic weight matrix is 0.009 , which passes the test at the $10 \%$ significance level. However, the Moran's I values are 0.033 and 0.031 respectively under the geographical and blend weight matrix, and both of them reject the null hypothesis at the $1 \%$ level, which indicates that the misallocation of land resources has significant spatial correlation characteristics in the economic, geographical, or blend spatial matrix of the economic and geographical weight matrix, however, the spatial correlation of misallocation of land resources simply at the level of economic development is less than that of geography and the integration of economy and geography.

Table 4 Spatial Correlation Test of Misallocation of Land Resources

\begin{tabular}{cccc}
\hline & $\begin{array}{c}\text { Economic Weight } \\
\text { Matrix EW }\end{array}$ & $\begin{array}{c}\text { Geographical } \\
\text { Woran's I }\end{array}$ & $\begin{array}{c}\text { Blend Weight } \\
\text { Matrix MW }\end{array}$ \\
\hline Coefficient value I & 0.009 & 0.033 & Moran's I \\
Value of expectation E & -0.000 & -0.000 & 0.031 \\
(I) & & & -0.000 \\
Standard deviation sd & 0.010 & 0.008 & 0.008 \\
(I) & & & \\
Z value & 1.011 & 4.007 & 3.880 \\
P value & 0.099 & 0.000 & 0.000 \\
\hline
\end{tabular}




\subsection{Estimation and Analysis Based on Spatial Correlation Effect}

Table 5 shows the results of the spatial correlation effect of misallocation of land resources on green technology innovation in the regions that are based on the Spatial Durbin Model analysis to test theoretical hypothesis 1 proposed in this paper. This part focuses on the analysis of the impact of misallocation ( $W m l r)$ of local ( $m l r$ ) and adjacent land resources on local green technology innovation $(g t)$. In view of the impact of misallocation of local land resources, under different weight matrix models, the measurement estimation coefficients of $m l r$ are all significantly negative, and the influence coefficients are $-1.119,-0.678$ and -0.592 , which indicate that the misallocation of land resources will indeed inhibit the regional green technology innovation, which is consistent with the theoretical expectation; the land is one of the important factors, and this conclusion is also in line with the view that factor market distortions will inhibit technological innovation of enterprises proposed by (Zhang et al. 2011). This is because the distortions in the structure and price of land resources allocation will not only attract polluting industries and inhibit the development of services and other industries, hinder the transformation and upgrading of industrial structure, but also result in excessively high land prices for residential and commercial services, contributing to the development of real estate-related industries. In contrast, it is not conducive to the development of technology research \& development and green technology innovation (Lai, 2019; Yang et al. 2014). In view of the impact of misallocation of adjacent land resources, in different weight matrix equations, the estimation coefficients of $\mathrm{Wmlr}$ are -4.548 , 4.877 , and -5.869 are all significantly negative at the $1 \%$. The possible reasons may be that the local governments perform the regional competition by making use of the land resources to achieve economic growth, attract foreign businesses and investment by means of selling industrial land at a low price, and even lowering environmental protection standards, which is not conducive to regional green technology innovation (Luo and Li 2014). Meanwhile, the inhibition of misallocation of adjacent land resources on local green technology innovation will affect the exchange and transfer of green technology between the regions, thus adversely affecting local green technology innovation. Therefore, the misallocation of local and adjacent land resources will hinder local green technology innovation, and it is tested by this conclusion that hypothesis 1 exist.

Table 5 Spatial Correlation Effect Estimation

\begin{tabular}{cccc}
\hline \multirow{2}{*}{$\begin{array}{c}\text { Model } \\
\text { Variable }\end{array}$} & \multicolumn{2}{c}{ Explained Variable: Green Technology Innovation $(\mathrm{gt})$} \\
\cline { 2 - 4 } & Economic weight & $\begin{array}{c}\text { Geographical } \\
\text { model }\end{array}$ & weight model \\
\hline mlr & $-1.119 * * *(-3.0)$ & $-0.678^{*}(-1.85)$ & $-0.592 *(-1.62)$ \\
ey & $-0.016(-0.12)$ & $0.365^{* * *}(3.16)$ & $0.475 * *(4.82)$ \\
fdi & $-0.010(-0.28)$ & $0.074 * *(1.91)$ & $0.099 * *(2.67)$ \\
gi & $0.004 *(2.35)$ & $0.004 * *(2.34)$ & $0.003 *(1.82)$
\end{tabular}




\begin{tabular}{cccc} 
grd & $0.172 * * *(3.90)$ & $0.126^{* * *}(2.92)$ & $0.141^{* * *}(3.38)$ \\
indus & $-0.009(-1.32)$ & $-0.003(-0.40)$ & $-0.005(-0.74)$ \\
$\mathrm{h}$ & $1.621 * * *(6.80)$ & $2.405^{* * *}(10.21)$ & $2.291 * * *(9.88)$ \\
Wmlr & $-4.548^{* * *}(-4.38)$ & $-4.877 * * *(-5.23)$ & $-5.869 * * *(-5.68)$ \\
Wey & $2.348^{* * *}(8.01)$ & $0.875^{* * *}(3.62)$ & $0.042(0.44)$ \\
Wfdi & $-0.271 * * *(-2.97)$ & $-0.357 * * *(-3.87)$ & $-0.489 * * *(-5.93)$ \\
Wgi & $0.004(0.81)$ & $-0.003(-0.69)$ & $-0.002(-0.60)$ \\
Wgrd & $0.133(1.25)$ & $0.300^{* * *}(3.50)$ & $0.381 * * *(5.28)$ \\
Windus & $-0.061 * * *(-4.74)$ & $-0.065 * * *(-4.88)$ & $-0.050^{* * * *}(-3.60)$ \\
Wh & $-1.715 * * *(-2.62)$ & $-2.980 * * *(-5.22)$ & $-2.188 * * *(-4.41)$ \\
rho & $0.177 * * *(5.12)$ & $0.295 * * *(7.57)$ & $0.272 * * *(6.45)$ \\
R2 & 0.345 & 0.366 & 0.376 \\
Log L & -5688.793 & -5653.952 & -5636.041 \\
\hline
\end{tabular}

393

394

395

Note: The values in brackets in the table represent $t$ statistics of the corresponding estimation coefficients, and ${ }^{* * *}, * *, *$ represent the significance level of $1 \%, 5 \%$, and $10 \%$, respectively. The spatial weight here is a blend weight matrix nested by geographical and economic weights, the same below.

As for other influencing factors, the estimation coefficients of economic development ( ey ) on green technology innovation are 0.365 and 0.475 . They pass the significance test at a $1 \%$ level, indicating that a higher level of economic development is conducive to developing green technology innovation. That is to say, the higher the level of local economic development is, the stronger the awareness and ability to promote the development of green technology will be, which is consistent with the research conclusion of (Guo, 2019). The influence coefficients of Wey on local green technology innovation is positive. This is because the radiation effect and driving effect of inter-regional economic development, and the economic development of adjacent areas will flow through human, capital, and other factors, thus promoting local green technology innovation. The geographical and blend weight matrix estimation coefficients of the level of attracting foreign investment ( $f d i$ ) are 0.074 and 0.099 , which passes the test at least at a significance level of 5\%, that is, there is a clean technology spillover effect with respect to the introduction of foreign investment by local governments, which supports the "polluting halo" hypothesis proposed by Tang et al. (2015) that foreign capital inflows can bring advanced green production technologies. However, the geographical and blend matrix influence coefficients of Wfdion local green technology innovation are -0.357 and -0.489 , which are significantly negative at the $1 \%$ level. This is probably because the neighboring regions lower the local environmental standards to attract foreign investment in the competition to achieve economic growth (Dong and Wang 2019). Thus, hindering the progress in green technology; in general, the hindering effect of Wfdi on green technology innovation is greater. Therefore, foreign direct investment is not conducive to the development of green technology innovation as a whole. The influence coefficients of administrative control ( ${ }^{g i}$ ) on green technology innovation are positive, at least at a significance level of $10 \%$. This conclusion is different 
from that of Dong and Wang (2019) because currently, governments, as the main force to implement and pass policies, can promote local green technology innovation by intervening in local innovation investment. Wgi has an inhibiting effect on the local green technology innovation; however, the effect is not significant. This is because, under administrative intervention, collaborative innovation between areas is subject to certain administrative restrictions, which fails to promote technology exchange and transfer between regions effectively. On the whole, the local effect of administrative control is greater than the neighboring effect, which is conducive to promoting the development of green technology innovation. The blend weight estimation coefficients of local ( grd ) and adjacent R\&D investment (Wgrd) are 0.141 and 0.381 , which passes the significance test at $1 \%$ level, namely, the improved level of regional $\mathrm{R} \& \mathrm{D}$ investment can stimulate the vitality of independent innovation of enterprises, and promote innovation in clean technologies and upgrading of production processes (Zhang and Wang 2017). This is consistent with the conclusion that government $R \& D$ investment can improve corporate green innovation proposed by (Bai et al. 2019). In addition, R\&D investment can also promote regional green technology innovation through the technology spillover effect ( $\mathrm{Lu}$ and Bai 2020). The industrial structure of both the local (indus) and adjacent areas (Windus) has an inhibiting effect on local green technology innovation, and the inhibiting effect of Windus passes the significance level of $1 \%$. This result is consistent with the view of Cheng et al. (2020), suggesting that industries that rely on resources will inhibit green total factor productivity. China's industrial structure is still dominated by heavy industry, and this mode of production will consume a lot of resources and damage the environment, thus hindering green technology innovation. Similarly, industries in adjacent areas may hinder local green technology progress by nearby transfer (Dongand Wang 2019). The influence coefficients of local ( $h$ ) and neighboring human capital $(W h)$ are significantly positive and negative, respectively, and pass the significance test at $1 \%$ level; that is, $h$ can promote the R\&D of green technology. This conclusion is consistent with the view of Kwan and Chiu (2015), indicating that human capital plays an important role in technology innovation; however, Wh has a significant inhibiting effect on local green technology innovation, which is because the competition for talents is fierce in all regions. As a result, the neighboring areas will inhibit local human capital growth by attracting talents, thus hindering green technology R\&D innovation. In general, the adverse effect of human capital in the neighboring areas on green technology innovation is greater than the local positive effect.

\subsection{Estimation and Analysis Based on Threshold Effect}

Table 6 shows the specific threshold value and significance test of the threshold effect of economic growth and environmental regulation of misallocation of land resources on green technology innovation obtained according to panel threshold estimation. According to Table 6, there is a threshold effect of economic growth and environmental regulation of misallocation of land resources on green technology innovation, and the threshold effect passes the $\mathrm{F}$ test at least at the significance level of $10 \%$.

Table 6 Significance Test and Confidence Interval of Threshold Variables

\begin{tabular}{llllllll}
\hline Thresholds & Number & F Value & $10 \%$ & $5 \%$ & $1 \%$ & Thresho & $95 \%$ \\
\hline
\end{tabular}




\begin{tabular}{|c|c|c|c|c|c|c|c|}
\hline & $\begin{array}{c}\text { of } \\
\text { Threshol } \\
\text { ds }\end{array}$ & & & & & $\begin{array}{c}\text { ld } \\
\text { Value }\end{array}$ & $\begin{array}{c}\text { Confidence } \\
\text { Interval }\end{array}$ \\
\hline $\begin{array}{c}\text { Economic } \\
\text { development (ey) }\end{array}$ & Single & $18.09 *$ & 15.638 & 19.024 & 22.223 & 1.400 & $\begin{array}{l}(1.3556, \\
1.410)\end{array}$ \\
\hline $\begin{array}{l}\text { Environmental } \\
\text { regulation (er) }\end{array}$ & Single & $\begin{array}{c}73.11 * * \\
*\end{array}$ & 39.047 & 41.811 & 55.023 & 0.251 & $\begin{array}{l}(0.231, \\
0.253)\end{array}$ \\
\hline
\end{tabular}

453

Table 7 shows the measurement estimation results of the threshold effect of economic development and environmental regulation. The influence coefficients of such variables as administrative control ( $g i$ ), R\&D investment ( $g r d$ ), etc., on green technology innovation in Table 5 is basically consistent with that in Table 2. Therefore, it will not be repeated here. This paper focuses on the analysis of the differences in the impact of misallocation of land resources on green technology innovation under different levels of economic development and different degrees of environmental regulation. In view of the level of economic development, when $e y \leq 1.400$, the estimation coefficient of misallocation of land resources ( $m l r)$ on green technology innovation is -3.130 , which passes the significance test at $1 \%$ level; when ey $>1.400$, although the estimation coefficient of misallocation of land resources $(\mathrm{mlr})$ on green technology innovation is -0.478 , it fails to pass the significance test. It can be seen from this that when the level of economic development is low, the misallocation of land resources has a significant inhibiting effect on green technology innovation; only when the level of economic development is high, the inhibiting effect of the misallocation of land resources on green technology innovation can be alleviated.

This conclusion is basically consistent with the theoretical expectation of hypothesis 2.1 , which indicates that the misallocation of land resources has a significant threshold effect on green technology innovation. This suggests that with the improvement of the level of regional economic development, the pressure on local governments to assess their fiscal revenue and performance is reduced, the green environmental preference of the local public increases accordingly, and the local governments sell land at low prices in the process of attracting investment (Cai et al. 2008). With this, the entry of low-quality and heavy polluting enterprises will be correspondingly reduced, which weakens the inhibiting effect of the misallocation of land resources on green technology innovation. In view of the impact of different degrees of environmental regulation, when $e r \leq 0.251$, the influence coefficient of the misallocation of land resources ( $m l r$ ) on green technology innovation is -4.354 , which passes the significance test at $1 \%$ level; when $e r>0.251$, the estimation coefficient of the misallocation of land resources $(\mathrm{mlr})$ is 0.578 , and the effect is not significant.

From the above analysis, we can see that when the degree of environmental regulation is low, the 
misallocation of land resources has an obvious hindering effect on green technology innovation; only when the degree of environmental regulation is raised to a certain level, the inhibiting effect of the misallocation of land resources on green technology innovation can be reduced. This conclusion is basically consistent with the theoretical expectation of hypothesis 2.2 , namely, the misallocation of land resources has a significant threshold effect on green technology innovation. This is because when the level of environmental regulation is low, in the process of competing for growth, the local governments will attract large amounts of polluting capital inflows by means of misallocation of land resources (Yang et al. 2014). With the improvement of the environmental regulation level, the vicious competition between local governments has been reduced, and the environmental protection standards have been further improved and inflow of clean capital is attracted, which drives the R\&D of local clean technology (Lu and Bai, 2020). This, in turn, reduces the adverse effect of misallocation of land resources on green technology innovation.

Explained variable Table 7 Estimation of Threshold Effect

\begin{tabular}{cc} 
Green technology innovation (gt) \\
\hline \multicolumn{2}{c}{ Misallocation of land resources (mlr) } \\
\hline Economic development (ey) & $\begin{array}{c}\text { Environmental regulation } \\
\text { (er) }\end{array}$ \\
\hline Estimated value & Estimated value \\
\hline$-0.162 * * *(-3.61)$ & $-0.152 * * *(-3.42)$ \\
$0.001(0.31)$ & $0.001(0.20)$ \\
$0.240 * * *(4.93)$ & $0.216 * * *(4.49)$ \\
$-0.028 * * *(-4.06)$ & $-0.024 * * *(-3.54)$ \\
$-0.556(-1.28)$ & $-0.388(-0.90)$ \\
$-3.130 * * *(-6.78)$ & $-4.354^{* * *}(-9.30)$ \\
$-0.478(-0.68)$ & $0.578(1.06)$ \\
$1.015^{* *}(2.00)$ & $0.652(1.30)$ \\
\hline
\end{tabular}

494

\section{Robustness test}

The above analysis has systematically verified the theoretical hypothesis proposed in this paper, and it shows that the misallocation of land resources has a spatial correlation effect and a threshold effect on green technology innovation. However, the data of misallocation of land resources adopted in the previous measurement study represents the proportion of industrial land by the proportion of agreed transferred land, which may deviate from the actual situation. Therefore, based on the practices of Li et al. (2016), some industrial land is sold in other ways, and the "reinvigoration" of the construction land reserve is also an important index to measure the degree of land resource allocation. Therefore, to investigate the allocation of regional land resources in a more comprehensive way, the ratio of the 
transferred area of industrial and mining storage land in different cities is used to measure the degree of misallocation of regional land resources, and a robustness test was performed. The higher the proportion of this index, the higher the degree of land resources' misallocation. The analysis results of the robustness test are shown in Table 8 and Table 9. The spatial correlation estimation results are shown in Table 8 , and the threshold estimation results are shown in Table 9. From the analysis of results, it can be seen that in view of spatial correlation effect estimation, after the core explanatory variables are replaced, the measurement estimation coefficients of the misallocation of local and adjacent land resources are significantly negative, that is, the misallocation of land resources still has a significant inhibiting effect on local green technology innovation; on the whole, the spatial spillover effect is basically consistent with the above results, which will not be repeated here. In view of the threshold effect, after the core explanatory variables are replaced, the misallocation of land resources still has an obvious threshold effect of economic development and environmental regulation on green technology innovation. According to Table 9, only when the level of economic development ey>1.719 and er $>0.256$ can the estimation coefficients of misallocation of land resources be not significant. That is to say, only when the economic development and the environmental regulation are raised to a certain level can the hindering effect of the misallocation of land resources on green technology innovation be alleviated. Based on the above analysis, it can be considered that the main measurement estimation results are relatively steady in this paper. Table 8 Spatial Correlation Effect Estimation (Robustness Test)

\begin{tabular}{|c|c|c|c|}
\hline \multirow[b]{2}{*}{ Variable } & \multicolumn{3}{|c|}{ Explained Variable: Green Technology Innovation (gt) } \\
\hline & Economic weight model & $\begin{array}{c}\text { Geographical weight } \\
\text { model }\end{array}$ & Blend weight model \\
\hline lem & $-0.333 * * *(-4.28)$ & $0.251 * *(-3.23)$ & $-0.233 * * *(-3.02)$ \\
\hline ey & $-0.042(-0.31)$ & $0.329 * * *(2.73)$ & $0.438 * * *(4.25)$ \\
\hline fdi & $0.012(0.31)$ & $0.086 * *(2.04)$ & $0.112 * * *(2.78)$ \\
\hline gi & $0.003 * *(1.93)$ & $0.003 * *(1.98)$ & $0.003(1.58)$ \\
\hline grd & $0.181 * * *(3.97)$ & $0.139 * * *(3.09)$ & $0.146 * * *(3.32)$ \\
\hline indus & $-0.004(-0.58)$ & $-0.001(-0.10)$ & $-0.004(-0.52)$ \\
\hline $\mathrm{h}$ & $1.603 * * *(6.37)$ & $2.345 * * *(9.35)$ & $2.153 * * *(8.71)$ \\
\hline Wlem & $-0.487 * * *(-2.50)$ & $-0.483 * *(-2.42)$ & $-0.560 * * *(-2.50)$ \\
\hline Wey & $2.192 * * *(7.16)$ & $0.765 * * *(3.05)$ & $0.003(0.03)$ \\
\hline Wfdi & $-0.219 * *(-2.17)$ & $-0.236 * *(-2.29)$ & $-0.374 * * *(-3.97)$ \\
\hline Wgi & $0.001(0.29)$ & $-0.005(-1.04)$ & $-0.003(-0.98)$ \\
\hline Wgrd & $0.113(1.01)$ & $0.283 * * *(3.17)$ & $0.372 * * *(4.93)$ \\
\hline
\end{tabular}




$\begin{array}{cccc}\text { Windus } & -0.063^{* * *}(-4.25) & -0.050^{* * *}(-3.42) & -0.029 *(-1.88) \\ \text { Wh } & -0.816(-1.17) & -2.903^{* * *}(-4.86) & -3.107 * * *(-6.43) \\ \text { rho } & 0.130^{* * *}(3.49) & 0.302^{* * *}(7.17) & 0.278 * * *(6.04) \\ \text { R2 } & 0.331 & 0.332 & 0.343 \\ \text { Log L } & -0.972 & -0.972 & -0.972\end{array}$

Table 9 Estimation of Threshold Effect (Robustness Test)

\begin{tabular}{ccc}
\hline Explained variable & \multicolumn{2}{c}{ Green technology innovation (gt) } \\
\cline { 2 - 3 } Core explanatory variable & Misallocation of land resources (lem) \\
\cline { 2 - 3 } Threshold variable & Economic development (ey) & $\begin{array}{c}\text { Environmental regulation } \\
\text { (er) }\end{array}$ \\
\cline { 2 - 3 } Variable & Estimated value & Estimated value \\
\hline fdi & $-0.107^{* *}(-2.25)$ & $-0.075^{*}(-1.60)$ \\
gi & $-0.001(-0.45)$ & $-0.001(0.67)$ \\
grd & $0203^{* * *}(4.07)$ & $0.179^{* * *}(3.63)$ \\
indus & $-0.027^{* * *}(-3.64)$ & $-0.013^{*}(-1.80)$ \\
$\mathrm{h}$ & $0.552(1.15)$ & $0.449(0.96)$ \\
Scale< $\mathrm{R}$ & $-4.229^{* * *}(-18.28)$ & $-0.815^{* * *}(-9.90)$ \\
$\mathrm{R}<$ Scale & $-0.008(-1.45)$ & $-0.107(-1.07)$ \\
Constant term & $0.089(0.17)$ & $-1.35^{* *} 0(-2.43)$ \\
\hline
\end{tabular}

\section{Conclusions and Policy Suggestions}

Based on the data of 252 cities in China from 2008 to 2017 and from 2009 to 2017, this paper adopts the empirical methods such as panel space measurement estimation and panel threshold estimation to systematically examine the impact of misallocation of land resources on green technology innovation. The study finds that local and adjacent land resources' misallocation significantly hinders the local green technology innovation. In terms of the threshold effect, the misallocation of land resources has significant threshold effects of economic development and environmental regulation on green technology innovation: when the level of economic development and the intensity of environmental regulation are low. The misallocation of land resources will significantly hinder green technology innovation; however, after the economic development and the environmental regulation are raised to a certain level, hindrance of the misallocation of land resources on green technology innovation will be weakened. In view of other influencing factors, the foreign investment attracted by local governments fails to significantly promote

538 green technology innovation. Furthermore, an administrative intervention cannot effectively promote the 539 coordinated development of green technology innovation among regions. The regional R\&D investment 540 can significantly improve the level of green technology innovation. Finally, the existing industrial 541 structure is not conducive to green technology progress, and human capital also does not significantly 
promote green technology innovation.

Based on the main findings, this study suggested that continuously deepen the reform of the fiscal and taxation system. The central government should adopt a more reasonable way of the distribution of local taxes, encourage local governments to put down the blind pursuit of "land finance", and avoid distortions in structure and price of the allocation of land resources to improve the technology innovation environment of enterprises. Local governments should also break down the interest barriers and policy barriers between regions, curb the "competition" among local governments to attract capital by land transfer, and accelerate the formation of a mechanism for coordinated regional development featured with orderly competition and green development. The government should accelerate the promotion of market-oriented reform of land. For this, it is proposed that the government continuously improve market-oriented reform of land, improve the efficiency of land resource use, and optimize the input of innovation elements and the environment for green technology innovation. Finally, the state should strengthen land transfer supervision, optimize the structure of land supply, reduce the space for enterprises to seek rent from local governments by making use of the land, and reduce the crowding-out effect on innovation input. In addition, it should also raise the local environmental standards, formulate strict environmental regulation policies, and prevent heavy polluting industries from entering as a result of the distortion of land allocation to stimulate local green technology progress. Finally, the state should vigorously promote high-quality development of local economies and increase investment in the research and development of green technology to promote the development of local green technology innovation.

\section{Compliance with ethical standards}

Conflicts of Interest The authors declare no conflicts of interest.

\section{References}

Bai JH, Bian YC (2016) Distortion of factor market and efficiency loss of China's innovative iroduction. China ind econ 11: 39-55 (In Chinese).

Bai Y, Song S, Jiao J, Yang R (2019) The impacts of government R\&D subsidies on green innovation: Evidence from Chinese energy-intensive firms. J. Clean. Prod. 233: 819-829.

Braun E, Wield D (1994) Regulation as a means for the social control of technology. Technol Anal Strateg 6(3): 259-272.

Cai F, Du Y, Wang MY (2008) The transformafion of economic development mode and the internal motivation of energy saving and emission reduction. Econ Res 6: 4-11, 36.

Cheng Z, Li L, Liu J (2020) Natural resource abundance, resource industry dependence and economic green growth in China. Resour. Policy 68: 101734.

Dong ZQ, Wang H (2019) Local-neighborhood effect of green technology of environmental regulation. China Ind Econ 1:100-118 (In Chinese).

Duan LZ, Li YS (2020) Empirical analysis of spatial spillover effect stems from land resource misallocation and economic fluctuation. Econ Geogr 40(3):207-215.

Fan LL, Zhu YY (2019) Enterprise environmental protection Expenditure, Government environmental protection subsidy and green technology innovation. Resour Dev and Market 35(1): 20-25, 37 (In Chinese).

Guellec D, Bruno VPDLP (2003) The impact of public r\&d expenditure on business r\&d. Ulb Institutional Repository 12(3): 225-243. 
Guo J (2019) The impact of environmental regulation on green technology Innovation -- Evidence of the "Porter Effect" in China. Financ Trade Econ 40(3):149-162 (In Chinese).

Guo YY, Zhang S, Zhang DP. (2018). Environmental regulation, Government R\&D funding and Green Technology Innovation: Inhibiting or Promoting? -- A research summary. East China Econ Manag 259(7): $42-49$ (In Chinese).

He XG (2014) Research on the optimal regulatory structure of green technology innovation -- Based on the dual interactive effect of $R \& D$ support and environmental regulation. Econ Manag 36(11):144-153.

Hsieh CT, Klenow PJ (2008) Misallocation and manufacturing TFP in China and India. 2008 Meeting Papers. Society for Economic Dynamics.

Huang Z, Du X (2017) Government intervention and land misallocation: Evidence from China. Cities 60: 323-332.

Jefferson GH, Huamao B, Xiaojing G, Xiaoyun Y (2006) R\&D Performance in Chinese industry. Economics of Innovation and New Technology 15: 345-366.

Jing WM, Zhang L (2014). Environmental regulation, opening to the outside world and green technology progress of Chinese industry. Econ Stud (9):34-47 (In Chinese).

Kwan LY, Chiu C (2015) Country variations in different innovation outputs: The interactive effect of institutional support and human capital. J. Organ. Behav. 36: 1050-1070.

Lai M (2019) Does the mismatch of land elements hinder the upgrading of China's industrial structure? -- Based on empirical evidence of 230 prefecture-level cities in China. Res Ind Econ 2: 39-49.

Li LX, Huang PY, Ma GG (2016) Land resource mismatch and productivity difference in Chinese industrial enterprises. Manag World 8: 86-96 (In Chinese).

Li WH, Bi KX, Sun B (2013) Research on the impact of environmental regulatory intensity on green technology innovation in pollution-intensive industries -- Empirical test based on panel data from 2003 to 2010. Res dev manag 25(06):72-81 (In Chinese).

Lu XH, Bai TT (2020) How does green technology innovation effectively reduce haze pollution? China Soft Sci 6: 174-182, 191.

Luo BL, Li SP (2014) Competition between local governments: land transfer and its strategic choice - Empirical evidence from China's provincial panel data (1993-2009). Acad Res 1: 67-78, 159160 (In Chinese).

Luo X, Zhang W (2020) Green innovation efficiency: A threshold effect of research and development. Clean Technol Envir 1:14.

Lv CC, Wang ZG (2019) Mechanism of action and empirical test of enterprise innovation by mismatching factor resources -- Based on empirical analysis of listed companies in manufacturing industry. Systems Engine Theory Practice 39(5):1137-1153 (In Chinese).

Miao Z, Chen X, Baležentis T, Sun C (2019) Atmospheric environmental productivity across the provinces of China: Joint decomposition of range adjusted measure and Luenberger productivity indicator. Energ. Policy 132: 665-677.

Mickwitz P, Hyvättinen H, Kivimaa P (2008) The role of policy instruments in the innovation and diffusion of environmentally friendlier technologies: Popular claims versus case study experiences. J. Clean. Prod. 16: 162-170.

Show PL, Lau PL, Foo DCY (2018) Green technologies: Innovations, challenges, and prospects. Clean Technol Envir 20: 1939.

Show PL, Lau PL, Foo DCY (2018) Green technologies: Innovations, challenges, and prospects. Clean Technol Envir 20: 1939.

Shu C, Xie H, Jiang J, Chen Q (2018) Is urban land development driven by economic development or fiscal revenue stimuli in china? Land Use Policy 77: 107-115.

Song M, Ma X, Shang Y, Zhao X (2020) Influences of land resource assets on economic growth and fluctuation in China Resour Policy 68: 101779. 
Song ML, Jin PZ (2016) Regional protection, resource msallocation and environmental welfare performance. Econ Res 51(12): 47-61.

Tang CF, Tan BW (2015) The impact of energy consumption, income and foreign direct investment on carbon dioxide emissions in Vietnam. Energy 79: 447-454.

Usui T, Furubayashi T, Nakata T (2017) Induced technological change and the timing of public R\&D investment in the Japanese electricity sector considering a two-factor learning curve. Clean Technol Envir. 19(5), 1347-1360.

Wang FZ, Guo XC. (2015) Impact of environmental regulatory intensity on green technology innovation in resource-based industries -- Empirical test based on panel data from 2003 to 2011. China Popul Resour Environ (S1):154-157 (In Chinese).

Wu H, Hu S (2020) The impact of synergy effect between government subsidies and slack resources on green technology innovation. J. Clean. Prod. 274: 122682.

Yang QJ, Zhuo P, Yang JD (2014) Industrial land conveyance and the investment quality race in the bottom line-empirical research based on the panel data of the Chinese prefecture-level cities from 2007 to 2011.Managt World 11: 24-34.

Yu YZ, Song CC, Rong KJ (2019) Misallocation of land resources and environmental pollution. Abstract Soc Sci 2: 52-54 (In Chinese).

Zhang J, Zhou XY, Li Y (2011) Factor market distortion restrains Chinese enterprise R\&D? Econ Stud 8:78-91 (In Chinese).

Zhang L, Cheng KW, Zhao JT (2019) Allocation of land resources and quality of economic development -- Cost of industrial land and total factor productivity. Financ Trade Econ 10: 126141.

Zhang X, Wang Y (2017) The impact of environmental regulation and R\&D investment on green technology innovation. Sci Technoly Prog Counter 34(17):111-119 (In Chinese). 


\section{Supplementary Files}

This is a list of supplementary files associated with this preprint. Click to download.

- GraphicalAbstract.docx 